\title{
"SE VOCÊ SE APOSENTAR E NÃO CONTINUAR TENDO PRAZER NA VIDA, VOCÊ VAI SE APOSENTAR PARA QUÊ?": UM ESTUDO SOBRE O TRABALHO DE DOCENTES APOSENTADOS DE UMA IFES
}

"If you retire and do not continue having fun in your life, you will retire to what?": A study on the work of retired faculty from an IFES"

"Si vous partez à la retraite et vous ne continuez pas ayant plaisir dans votre vie, pourquoi vous partirez à la retraite?": Un étude sur le travail de professeurs retraités d'une IFES"

“Si usted se retira y no continúa teniendo placer en su vida, usted se retirará para qué?”: Un estudio sobre el trabajo de docentes jubilados de una IFES"

Carla Vaz dos Santos Ribeiro1

http://orcid.org/0000-0002-5518-9619.

Doutorado em Psicologia Social pela Universidade do Estado do Rio de Janeiro. Professora Associada da Graduação e do Mestrado em Psicologia da Universidade Federal do Maranhão. Membro do grupo de pesquisa Psicodinâmica e Clínica do Trabalho na ANPEPP e membro da Rede Universitas -BR. Universidade Federal do Maranhão, São Luís, Maranhão, Brasil.

Ana Flávia Moniz Costa ${ }^{2}$ https://orcid.org/0000-0002-4722-3274. Mestrado em Psicologia pelo Programa de Pós-Graduação em Psicologia da Universidade Federal do Maranhão - UFMA, Pós-Graduação em Planejamento e Gestão Estratégica de Recursos Humanos pelo Centro Universitário do Maranhão - UniCEUMA e Graduação em Psicologia pela UFMA. Pesquisadora do Grupo de Pesquis a sobre Trabalho docente na educação superior, subprojeto 4 do Rede Universitas - BR. Psicóloga concursada da UFMA, desenvolvendo atividades no Departamento de Gestão de Pessoas da Pró-Reitoria de Recursos Humanos.

Universidade Federal do Maranhão, São Luís, Maranhão, Brasil.

Valéria Maria Lima Cardoso ${ }^{3}$ https://orcid.org/0000-0002-8346-7735. Mestrado pelo Programa de Pós-graduação em Psicologia pela Universidade Federal do Maranhão e Graduação em Psicologia pela Universidade Federal do Maranhão. Psicóloga do Instituto Federal do Maranhão atuando no Subsistema da Atenção à Saúde Integrada do Servidor Público Federal. Instituto Federal do Maranhão, São Luís, Maranhão, Brasil.

Brenda Barros Machado https://orcid.org/0000-0001-6864-6148. Mestranda do Programa de Pós-graduação em Psicologia da Universidade Federal do Maranhão. Universidade Federal do Maranhão, São Luís, Maranhão, Brasil.

${ }^{1}$ carlavazufma@gmail.com

2anafmoniz@hotmail.com

${ }^{3}$ val limacardoso@yahoo.com.br

4 brenda.b.machado@hotmail.com

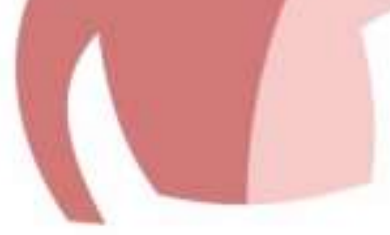




\section{Resumo}

O presente artigo buscou investigar aspectos que influenciam docentes inativos de uma Instituição Federal de Ensino Superior (IFES) no retorno ao trabalho. Foram entrevistados sete docentes que regressaram à Instituição depois da aposentadoria e, dentre eles, seis voltaram ao labor sem nenhuma vantagem financeira. Procurou-se analisar o significado dessa fase de transição para os entrevistados, e como se deu a decisão de retornar ou permanecer na Instituição após a aposentadoria. Constatou-se que, apesar de afirmarem que atualmente possuem uma rotina mais autônoma, alguns descrevem um cotidiano laboral bastante intensificado. Ao enfatizarem que a docência ocupa um lugar crucial em suas vidas, confirmam a relevância deste trabalho na constituição de suas subjetividades e a dificuldade de ruptura do vínculo laboral e de aceitação da aposentadoria .

Palavras-chave: Psicodinâmica do Trabalho; Sentido do Trabalho. Aposentadoria; Subjetividade.

\section{Abstract}

The present article sought to investigate as pects that influence inactive profes sors of a Federal Institution of Higher Education (IFES) in the return to work. Seven professors who returned to the Institution after retirement were interviewed, and among them six returned to work without any financial advantage. We sought to analyze the significance of this transition phase for the interviewees, and how the decision to return to or stay in the institution after retirement was made. It was found that, although they affirm that they currently have a more autonomous routine, some describe a highly intensified Labor Day. By emphasizing that teaching occupies a crucial place in their lives, they confirm the relevance of this work in the constitution of their subjectivities and the difficulty of breaking the employment bond and accepting retirement.

Keywords: Work Psychodynamics; Sense of work; Retirement; Subjectivity.

\section{Résumé}

Le présent article a cherché à decouvrir les raisons qui influencent les professeurs retraités d'IFES à retourner au travail. Ont été interviewés sept professeurs, tous repartis travailler bien qu'à la retraite. Parmi eux, un professeur reçoit un salaire en plus de sa pension de retraite, alors que les six autres ne reçoivent aucun avantage financier. Le but de la recherche est d'analyser cette transition du passage du statut d'actif à celui de retraité dans un premier temps et dans un second temps, celui de retraité au statut d'actif. Et ensuite comprendre comment cette décision a été prise, à savoir quels sont les facteurs qui entrent en jeu dans ce retour ou non à l'activité professionnelle. À la fin de la recherche, nous avons constaté que, malgré les aspects négatifs de leur travail, et bien qu'étant moins sollicités puisque à la retraite, ils affirment retrouver une part de leur identité. Ils avancent également que l'enseignement représente un champ essentiel de leur épanouissement personnel, et jugent difficile cette rupture des liens tissés au travail et leur propre acceptation d'être "un retraité".

Mots-clés: Psychodinamique du travail; Sens du travail; Retraite ; Subjectivité.

\section{Resumen}

Este artículo investigó aspectos que influencian a los profesores inactivos de una IFES que regresan a la educación después de la jubilación. Siete profesores que regresaron a la Institución después de retiro, fueron entrevistados, entre ellos, seis regresaron al trabajo sin ninguna ventaja financiera. Se buscó analizar el significado de esta fase de transición para los entrevistados y cómo se tomó la decisión de regresar o permanecer en la Institución des pués de la jubilación. Se constató que, aunque dicen que tienen una rutina de trabajo más autónoma, algunos están trabajando más que antes. Cuando enfatizan que el trabajo como docente no es como los demás, muestran que su subjetividad todavía está marcada para este lugar, lo que confirma la dificultad de abandonar de esse papel y, en consecuencia, la dificultad de aceptar la jubilación.

Palabras clave: Psicodinámica del Trabajo; Sentido del Trabajo; Retiro; Subjetividad. 


\section{INTRODUÇÃO}

Abordar os desafios impostos pelo afastamento do mundo laboral implica em refletir sobre a centralidade do trabalho na sociedade contemporânea. A possibilidade de rompimento com o trabalho, em um contexto que enaltece e valoriza o sujeito produtivo, favorece temores frente ao risco de desfiliação e segregação no não lugar. Nesse contexto, as vivências dos trabalhadores em processo de aposentadoria são distintas e complexas. Não é incomum o sentimento de inutilidade e o esvaziamento de sentido da vida (Ribeiro \& Léda, 2018; Zanelli, Silva \& Soares, 2010).

Diante das incertezas dos impactos da transição do papel de trabalhador para o papel de aposentado, alguns recuam, adiando a aposentadoria; outros efetivam a ruptura e seguem caminhos desvinculados da vida profissional; e parte opta por retornar ao trabalho, mesmo na condição de aposentado (Freire et al., 2018). Nessa direção, este estudo ${ }^{5}$ realizou análise sobre um grupo específico - o de docentes inativos que retornam às atividades na docência depois da aposentadoria.

Para o desenvolvimento desse estudo, lançou-se mão do referencial teórico metodológico fundamentado nos princípios do materialismo histórico-dialético, implicando o entendimento do sujeito como ser social e histórico, que intervém na realidade à qual está inserido, e sofre as determinações dessa mesma realidade. Conceitos da abordagem da Psicodinâmica do Trabalho também foram priorizados e articulados, comparecendo como referencial privilegiado na fundamentação teórica de categorias-chave da pesquisa.

Procurou-se investigar aspectos que influenciam docentes inativos de uma IFES no retorno ao trabalho. Para tal, algumas questões norteadoras foram delineadas, tais como: Qual tipo de retribuição os docentes inativos recebem para continuar trabalhando sem ter obrigações contratuais? Há "remunerações sociais" que justifiquem essa permanência na docência? A continuidade no exercício da docência poderia estar mais atrelada ao medo da inatividade do que ao prazer vivenciado no cotidiano laboral? O retorno ao trabalho na Instituição seria benéfico para a saúde dos docentes inativos?

Para o alcance do objetivo proposto e investigação das questões supracitadas, este artigo

\footnotetext{
${ }^{5}$ Este estudo está vinculado a um projeto de pesquis a maior - coordenado por Ribeiro, iniciado em 2016, ainda em andamento -, que tem como tema central a análise das repercussões da aposentadoria na subjetividade de docentes de uma IFES. O estudo conta com financiamento da Fundação de Amparo à Pesquisa e ao Desenvolvimento Científico e Tecnológico do Maranhão (FAPEMA), e com a participação de discentes da graduação e pós graduação em Psicologia da Universidade Federal do Maranhão (UFMA), e de psicólogos titulados no Programa de Pós-graduação em Psicologia da UFMA.
} 
foi dividido em três eixos: no primeiro aborda-se sobre as principais categorias teóricas elencadas na pesquisa (trabalho, subjetividade e aposentadoria); no segundo eixo, discorre-se sobre o método utilizado, dando destaque aos procedimentos concernentes à coleta e análise dos dados, e; por fim, no terceiro eixo, apresenta-se a discussão de resultados e as considerações finais.

\section{Trabalho e Subjetividade}

Na sociedade contemporânea, a identidade de trabalhador é de extrema importância na vida dos sujeitos. As pessoas, ao serem questionadas acerca da sua identidade, costumam evocar o seu nome e a referência profissional que as define, enfatizando a centralidade do trabalho na vida de todo sujeito adulto.

Entretanto, nem sempre foi assim. Segundo Borges e Yamamoto (2004), a concepção de trabalho que se tem hoje foi construída a partir do nascimento do capitalismo, em função de uma ideologia que atribui elevada centralidade ao trabalho, associada a uma ética do cumprimento do dever. A religião, nessa época, foi uma das responsáveis pela disseminação do trabalho como vocação, como "chamado de Deus". O trabalho passou a ser visto como obrigação religiosa, como um caminho para a redenção ao qual todo homem de bem deveria obedecer, pois era considerado como expiação pelos pecados da vida terrena.

Castel (1998, p. 24) concebe o trabalho como "suporte privilegiado de inscrição da estrutura social", e acredita que, por meio dele, as pessoas podem se inserir em redes de sociabilidade e de proteção social, constituindo-se como um integrador das diversas áreas que fazem parte da vida de um sujeito. É a inserção pela atividade laboral que posiciona o sujeito em um lugar na sociedade. O trabalho é a "integração das integrações" familiar, escolar, social, política, profissional (Castel, 1998, p. 533).

Antunes (2011) considera o trabalho como ato social de produção e reprodução da existência do ser social por meio dos laços de cooperação presentes nesse contexto, sendo que é a partir do trabalho que o homem se diferencia dos não humanos, por meio da atividade teleológica, ato consciente que estabelece, inicialmente, as etapas do processo de trabalho, antes da sua execução. O trabalho se configura enquanto "elemento fundante de realização do ser social, condição para sua existência; é o ponto de partida para a humanização do ser social" (Antunes, 2011, p. 144).

Constata-se, dessa forma, que o trabalho comparece como elemento central, configurando-se como fonte de pesquisa essencial para compreensão da constituição do ser 
social. Jamais pode ser considerado como neutro ou pouco significativo. Considera-se o mesmo como uma categoria-chave que "[...] ou joga a favor da saúde ou, pelo contrário, contribui para sua desestabilização e empurra o sujeito para a descompensação.” (Dejours, 2011c, p. 164).

Para Dejours (2011b, p. 448), "o trabalho é uma 'atividade coordenada útil, o que engloba os empregos assalariados, mas pode facilmente ultrapassá-los. 'A atividade' implica um objetivo a ser cumprido, e ainda um possível afastamento da tarefa prescrita." O autor afirma que o trabalho é aquilo que o sujeito coloca em prática, por meio da mobilização subjetiva, preenchendo a lacuna entre o trabalho real e o trabalho prescrito, para dar conta das tarefas que the são designadas. Dejours e Abdoucheli (2007) entendem o trabalhador enquanto sujeito ativo, e esclarece que:

[...] o sujeito pensa a sua relação com o trabalho, produz interpretação de sua situação e de suas condições, socializa estas últimas em atos intersubjetivos, reage e organiza se mentalmente, afetiva e fisicamente, em função de suas interpretações, age, enfim, sobre o próprio processo de trabalho e traz uma contribuição à construção e evolução das relações sociais de trabalho (p. 140).

Martins (2011) complementa que a Psicodinâmica do Trabalho concebe o homem como um sujeito ativo, que não aceita o seu sofrimento de forma passiva, lutando contra as formas de organização do trabalho que prejudicam a sua saúde, permanecendo num constante movimento para não adoecer. Nesse movimento, os trabalhadores se utilizam de alguns mecanismos ao lidarem com o sofrimento imposto pelo real do trabalho, por meio do enfrentamento dos constrangimentos vividos na organização do trabalho ou por meio de utilização de estratégias defensivas para lidarem com esse sofrimento.

O sofrimento é inerente ao contexto de trabalho: ou seja, não há como pensar em trabalho apartado do sofrimento. Ao trabalhar, o sujeito se confronta com a realidade do trabalho e suas resistências que acarretam em sentimentos de frustração e de impotência, diante do fracasso da técnica e do conhecimento. Esse sofrimento gerado pelo real do trabalho é o que vai ser o ponto de partida para que o sujeito, por meio da mobilização subjetiva, ultrapasse o trabalho prescrito e imprima sua subjetividade no trabalho.

Para Martins (2013, p. 437), o trabalho funciona "[...] como uma proteção da subjetividade com relação ao mundo, com o poder de revelar a própria subjetividade, transformando-a [...]", configurando-se como uma forma de construção do sujeito no campo social, onde o sujeito busca reconhecimento pelo que faz através do olhar do outro.

Dejours (2004) esclarece que a proteção da subjetividade se dá devido ao engajamento pessoal para a transformação do sofrimento em prazer. Dessa forma, o sofrimento se caracteriza 
enquanto uma "[...] impressão subjetiva do mundo e origem do movimento de conquista do mundo" (Dejours, 2004, p. 28). Ou seja, é a partir do sofrimento que a subjetividade é colocada à prova, movimento este que permite que a subjetividade se revele, transforme e se engrandeça .

O supracitado autor defende que esse movimento de apropriação do mundo, por meio do engajamento do sujeito na atividade, é o que forma a inteligência do corpo. A relação prolongada do corpo com a tarefa é o que vai permitir a constituição da inteligência. Dessa forma, o trabalho engloba toda a personalidade do sujeito, em que toda a sua subjetividade é convocada no ato de trabalhar.

Frente à importância do trabalho para a constituição da subjetividade, levanta-se alguns questionamentos: O quanto é possível ser reconhecido, valorizado e desfrutar de um lugar social afastado do trabalho? Como manter essa retribuição simbólica na condição de docente inativo?

No tópico a seguir, pretende-se abordar o desafio de vivenciar a aposentadoria como um tempo de "não trabalho", e ocupação de um "não lugar" em uma sociedade que enaltece o sujeito ativo e produtivo.

\section{Aposentadoria: Tempo de "não trabalho" e ocupação de um "não lugar"?}

A vivência de afastamento do cotidiano laboral é desafiadora. A destituição de um sentimento de pertença, e de uma vida social atrelada ao trabalho, faz emergir vivências de desfiliação e exclusão no "não lugar" (Ramos, Tittoni \& Nardi, 2008). A aposentadoria - como um dos mais relevantes processos de mudança e ruptura na vida das pessoas adultas - tem, no "não trabalho", acentuada repercussão na subjetividade. Comparece como um dos períodos de maior impacto e de transformações nas relações familiares e sociais. Os aposentados podem vivenciar ganhos e perdas, incluindo desde o desprendimento de obrigações com o cotidiano de trabalho até a perda de papéis, de status e do próprio sentido da vida (França et al, 2013; Santos, 1990).

Entretanto, em uma sociedade que eleva o trabalho à categoria central, a aposentadoria carrega estereótipos negativos de ociosidade e inutilidade. A possibilidade de afastamento do trabalho é frequentemente associada a temores de vivências de solidão, de tédio e de exclusão, principalmente para os indivíduos que priorizaram a dimensão profissional em detrimento de outras dimensões, como pessoal e social (Ribeiro \& Leda, 2018).

De acordo com Zanelli, Silva e Soares, (2010) a aposentadoria é um processo vivenciado como um momento de perda de referência de vida, sendo que esse processo é acompanhado por outras perdas advindas do envelhecimento, com a diminuição da força muscular, da mobilidade 
e resistência orgânica, o que o torna ainda mais doloroso:

O "descarte da laranja" ou que ficou conhecido como um papel sem papel significa, para o descartado, a perda da posição, dos amigos e das rotinas, do número de referência, a transformação dos valores, das normas e das rotinas, e submissão à condição que agridem a autoestima e a imagem de si mesmo. Em outras palavras coloca-se em xeque a identidade pessoale ocupacional do trabalhador (Zanelli, Silva \& Soares, 2010, p. 32).

Por ser um fenômeno complexo, a aposentadoria pode se apresentar como ruptura para os sujeitos que têm na atividade laboral o foco central de suas vidas. O afastamento do trabalho implica "em abdicar de seu lugar no mundo e de sua posição social ao romper o convívio cotidiano com os colegas de profissão, perdendo também a identidade profissional que é o fio norteador de seu projeto de ser" (Roesler, 2012, p. 283). Nesses termos, essa fase de transição tende a ser marcada pelas limitações impostas pela idade, pela dúvida, pelas expectativas e planos sobre o que fazer, e pelo medo do desconhecido atrelado à possibilidade de não se reconhecer.

Ramos, Tittoni e Nardi (2008) afirmam que o processo de exclusão e desfiliação do mundo laboral tende a ocasionar, aos que se aposentam a dificuldade de preservar padrões e estilos antes vivenciados, impondo a busca de estratégias de reconstruções e de ressignificações. A partir desta perspectiva, a aposentadoria deve ser entendida enquanto um processo, e não um momento pontual, como enfatizam França et al (2013), período que compreende tomadas de decisões que implicam na necessidade de reestruturação de rotinas e hábitos. Demanda reorganização de um cotidiano dedicado ao labor, com a substituição do tempo do trabalho por um tempo dedicado para outras atividades para além da vida profissional.

Neste cenário, a preparação para a aposentadoria se torna fundamental. É imprescindível a redefinição de papéis, a reinvenção de ocupações, o estabelecimento de novos objetivos de vida. O maior risco frente ao tão importante processo de afastamento da atividade laboral é "a freada brusca". É necessário o planejamento da transição de uma vida focada no trabalho para uma vida em que o trabalho possa comparecer como atividade assessória, ou até mesmo ser destituído de maior valor.

Defende-se a relevante identificação de caminhos que permitam desacelerar e permanecer ativo. É importante investigar se uma das principais razões que levam os docentes inativos entrevistados a retornarem ao trabalho seria o receio de enfrentar um cotidiano desprovido de maiores rotinas e obrigações - retrato da temida ociosidade. 


\section{MÉTODO}

Para a análise do tema em questão, devido ao caráter multifacetado do objeto de estudo, adotou-se como proposta teórico-metodológica: a abordagem conceitual da Psicodinâmica do Trabalho e da Psicologia Sócio-Histórica, com base no referencial do materialismo históricodialético, pois, como bem nos sinalizam Silva e Heloani (2007, p. 105): “A proposta teóricometodológica da psicodinâmica do trabalho caracteriza-se como crítica e interdisciplinar, passível de engendrar transformações nos aspectos patogênicos da gestão e da organização do trabalho, assim como pode articular-se ao referencial teórico do materialismo históricodialético".

A Psicologia Sócio-Histórica concebe o homem como um sujeito social, ativo e histórico. Suas categorias fundamentais são: subjetividade, atividade, consciência, identidade e linguagem. É uma psicologia com caráter mais crítico, pois procura, segundo Gonçalves (2003, p. 286) “[...] evidenciar as condições materiais que estão na base da constituição da subjetividade, explicitando mediações presentes nesse processo", e, para isso, utiliza-se da contradição do referencial materialista histórico-dialético.

Assim como a Psicologia Sócio-Histórica, a Psicodinâmica do Trabalho também procura ir além das aparências do fenômeno, permitindo uma análise dinâmica do contexto de trabalho. De acordo com Mendes (2007, p. 29), a Psicodinâmica do Trabalho procura analisar o contexto de trabalho caracterizado "pela atuação de forças visíveis e invisíveis, objetivas e subjetivas, psíquicas, sociais, políticas e econômicas que podem ou não deteriorar esse contexto, transformando-o em lugar de saúde e/ou de patologias e de adoecimento". Seu objeto de estudo são as relações dinâmicas entre organização do trabalho e as formas de subjetivação provocadas por essa dinamicidade, caracterizadas pelas vivências de prazer e sofrimento, pelas estratégias de ação, para dar conta das contradições da organização do trabalho, pelas patologias sociais, pela saúde e pelo adoecimento.

Com esse embasamento teórico, para a pesquisa empírica foi utilizado um roteiro de entrevista semiestruturada como instrumentos de coleta de dados, composto de onze perguntas que abordaram os seguintes temas: sentido do trabalho, aposentadoria, retorno ao trabalho, prazer e sofrimento no trabalho. A opção por este instrumento se deu porque ele permite conhecer as opiniões daqueles que vivenciam a realidade estudada; entender as motivações, os significados, os valores que sustentam as visões de mundo, dando voz ao outro e compreender sobre de que perspectiva ele fala. Propicia, também, a criação de um espaço mais flexível, no qual o entrevistador possa adotar uma postura menos diretiva para favorecer o diálogo mais 
aberto, oportunizando que o entrevistado possa se expressar mais livremente, fazendo surgir novos aspectos significativos sobre o tema (Fraser \& Gondim, 2004).

A pesquisa foi realizada com docentes aposentados de uma IFES, que retornaram às atividades acadêmicas. Foram entrevistados 7 (sete) docentes que permaneceram ou retornaram ao trabalho depois da aposentadoria. Ressalta-se que 6 (seis) deles trabalham atualmente de forma voluntária na Instituição, uma vez que é permitido esse tipo de vínculo. Apenas 3 (três) possuem contratos de voluntários assinados. Somente 1 (um) tem vantagem financeira a partir de um vínculo de prestação de serviços.

O tempo de serviço remunerado na Instituição dos entrevistados varia de 23 a 47 anos. Desses professores, 4 (quatro) estão ligados a programas de Pós-Graduação e 2 (dois) ligados a Departamentos. A tabela 1 mostra a idade e o tempo de contribuição enquanto docentes ativos pertencentes ao quadro de efetivos.

Tabela 01: Idade e tempo de trabalho dos entrevistados

\begin{tabular}{c|c|c}
\hline \multicolumn{1}{c}{ Entrevistados } & \multicolumn{1}{c}{ Idade } & Tempo de trabalho até a Aposentadoria \\
\hline E1 & 74 & 39 \\
E2 & 65 & 29 \\
E3 & 73 & 47 \\
E4 & 58 & 24 \\
E5 & 85 & 28 \\
E6 & 69 & 33 \\
\hline
\end{tabular}

Fonte: Sistema Integrado de Gestão de Recursos Humanos (SIGRH, 2018).

Os princípios éticos dessa pesquisa estão baseados na Resolução no 510/2016, que rege as pesquisas em ciência humanas e sociais. Os docentes, após concordância de participação, assinaram o Termo de Consentimento Livre Esclarecido (TCLE). Todas as entrevistas foram gravadas mediante a autorização dos sujeitos pesquisados, sendo que se optou por identificálos pelo nome "Entrevistado" ou "Entrevistada", seguidos de numeração, para preservar a identidade dos participantes.

Como referencial para análise dos dados coletados, adotou-se a Teoria Social do Discurso proposta por Fairclough (2008), que pensa o discurso em sua relação dialética com a estrutura social. A referida teoria se baseia em um modelo tridimensional de análise do discurso, que consiste em três princípios metodológicos autônomos, porém, complementares: a análise de textos falados e/ou escritos; a análise do processo de produção, distribuição e consumo de textos (que ele denomina de "prática discursiva"), e; a análise de acontecimentos discursivos como práticas socioculturais. Compreende o discurso em sua relação dialética com a estrutura social, favorecendo a investigação de práticas sociais como práticas ideológicas, perpassadas 
em suas condições materiais sócio-históricas de manifestação da realidade subjetiva.

\section{DISCUSSÃO DOS RESULTADOS}

Para a apresentação da discussão dos resultados, articulou-se os discursos dos entrevistados com as seguintes categorias: sentido do trabalho, reconhecimento, aposentadoria, prazer e sofrimento. Cada uma das supracitadas categorias correspondeu a um tópico da discussão apresentada. Cabe destacar que as análises e reflexões oriundas do projeto de pesquisa maior sobre aposentadoria - que as autoras deste artigo integram -, também contribuíram para a construção deste artigo.

\section{O Sentido do Trabalho e o Vínculo com a Instituição}

Partindo da concepção do trabalho enquanto elemento central na sociedade contemporânea, Castel (1998, p. 578) afirma que este "continua sendo uma referência não só economicamente, mas também psicologicamente, culturalmente e simbolicamente, como provam as reações dos que não o têm”. Significa dizer que é na vivência do afastamento laboral que a relevância do lugar do trabalho se faz presente.

Com base nos relatos coletados, foi possível notar o quanto é difícil para os professores aposentados lidarem com a ameaça do "não trabalho" frente à alternativa de desvinculação institucional. Ao falarem da sua história de vida pessoal, frequentemente se remetem ao lugar de docente, sempre ressaltando a importância de ser professor e de poder contribuir para a Instituição à qual estão vinculados há muitos anos. Alguns deles iniciaram suas atividades como monitores, construindo sua história de relação com o trabalho na Instituição desde a graduação .

Verificou-se que a centralidade do trabalho é algo que está em evidência no discurso dos sujeitos entrevistados. Revelaram elementos intrigantes na relutância em se desvincular da Instituição, pois, indiscutivelmente, permanecem atrelados à docência, independentemente de obrigações contratuais e de vantagens financeiras.

Eu acho que o trabalho docente, efetivamente você tem uma dificuldade de rompimento. No meu caso se acresce algo, que no serviço social é uma marca, é muito uma ideia de militância. Otrabalho não é só trabalho, o trabalho, o saber, aquilo que a gente reflete. Tem que ser algo que se direciona a uma causa, um propósito. Então isso define vínculos realmente para além dessa questão do trabalho que cessou no dia que você teve no diário oficial a sua aposentadoria publ icada, como se o trabalho fosse mais que isso. Então é algo que tem um sentido. (Entrevistada 2). 
Eu costumo dizer que a docência é uma cachaça, porque ela é viciante. A docência não é como qualquer trabalho, como os outros trabalhos em que as pessoas se desvinculam mais rápido. A pessoa não está professor, ela é professor, existe essa diferença entre ser e estar (Entrevistada 4).

No que concerne ao professor aposentado, a identidade profissional é carregada de muito investimento simbólico, pois o trabalho docente foi o que o constituiu e ainda o constitui como sujeito. As atribuições do professor universitário vão muito além de ministrar conteúdos, uma vez que ele é também formador de cidadãos.

Para alguns dos entrevistados que foram fundadores dos seus cursos, a opção por continuar trabalhando na universidade é a possibilidade de acompanhar os resultados do seu investimento de décadas de contribuição. Para estes docentes, o trabalho aparece como algo de extrema importância, sendo comparado à própria vida, como aponta o relato da Entrevistada 5, de 84 anos:

O [setor ao qual pertence] é o meu oxigênio, de que no dia que eu sair, morreu a professora [nome] (risos), com tanto amor que eu faço a isso. Então a minha vida toda é dedicada a isso. E eu estou aqui, enquanto me "mantiverem" eu não saio, [grifo nosso], só quando mesmo não puder mais vir aqui, mas todo dia eu estou aqui, de manhã e de tarde (Entrevistada 5).

O desejo de continuarem sendo úteis para a Instituição, e para a sociedade e o lugar que o trabalho ocupa na vida desses docentes, são alguns dos fatores que os fazem optar por permanecer ou retornar à atividade, depois de aposentados, dificultando ou postergando o momento do desligamento. Dejours (2011a) sinaliza que há uma retribuição para a contribuição utilitária do trabalho do sujeito, e a utilidade do trabalho se faz necessária para diferenciá-lo de qualquer outra atividade, seja ela esportiva, de lazer, enfatizando o seu caráter de utilidade técnica, social ou econômica.

[o retorno] é o compromisso com a sociedade de melhorar a pesquisa e o compromisso da gente ser um país independente, uma independência cientificamente, tecnologicamente (Entrevistado 1).

Eu devo muito à [nome da Instituição], pois meu histórico de vida foi muito difícil. Eu passei no vestibular grávida, tranqueio prime iro período e logo depois engravidei de novo, então eu tive duas filhas num intervalo de um ano e meio, então não foi fácil. Quando eu entrei aqui, entrei só com a graduação, fiz especialização e mestrado quando tive oportunidade. Me afastei pro doutorado, então, talvez por isso, eu acho que eu deva continuar contribuindo [grifo nosso] (Entrevistada 4).

Por tudo isso eu acho que eu tenho contribuído para a melhoria da saúde do meu país, do meu estado, principalmente. Hoje nossas fórmulas são solicitadas em todo Brasil, e eu sinto que dei, e continuo dando uma contribuição muito boa (Entrevistada 5).

A entrevistada 2 enfatiza a centralidade do trabalho para a sua vida, sinalizando o risc o 
de desagregação pessoal diante da possibilidade de aposentadoria. O depoimento que segue vai ao encontro do que Antunes (2005) defende sobre a importância de trabalho, ao afirmar que uma vida cheia de sentido fora do trabalho está muitas vezes relacionada ao próprio sentido encontrado na atividade laboral.

Então eu acho que pra trabalhos dessa natureza, gente, esse trabalho a gente nem sabe a hora que ele começa e a hora que ele termina, você leva pra casa, você olha de noite, você tá acompanhando os alunos. Não tem um fim. [...] É algo internalizado, então pra você tirar tudo isso você tem que tirar com muita calma, senão você pode até se desagregar, desagregação pessoal. Meu Deus, e agora, o que eu faço? Você se vê sem sentido [grifo nosso]. (Entrevistada 2).

No discurso desses docentes percebe-se a dificuldade de rompimento com a Instituição e com o trabalho que desenvolvem, por considerarem a docência uma atividade diferenciada, que gera conhecimentos e que forma pessoas e futuros profissionais. A necessidade de continuarem desenvolvendo esse papel e serem reconhecidos como docentes que contribuem para o desenvolvimento da sociedade que fazem parte é elemento fundamental para a constituição da sua subjetividade, mostrando que, apesar da idade avançada, ainda têm muito a contribuir.

\section{A Importância do Reconhecimento}

Dejours (2011c) salienta que o reconhecimento no trabalho trata de uma retribuição à contribuição e engajamento dados pelo sujeito, sendo possível que o sofrimento oriundo da organização do trabalho seja ressignificado em prazer pela via do reconhecimento. Os discursos dos docentes entrevistados ressaltam a importância do reconhecimento da atividade laboral, e destacam a importância de serem valorizados por ex-alunos e sociedade.

Aí, eu fui lá com os documentos, fui pegar um fila, sabe fila chata? Aí, um menino me chamou, "professor, faz favor, deixa isso aqui, o senhor senta ai e me espera", ai daqui a pouco ele me chamou e falou "olha ai, 48 horas o senhor vem pegar sua certidão", e a fila continuou. Aí, fui embora. Não perguntei nada pra ele. Mas o fato de ele ter me reconhecido... passou num concurso federal, estava lá, concursado... mas ele me chamou de professor. Então é uma coisa que eu convivo muito em São Luís, já são frutos das passagens que você teve dentro da Instituição. [...] numa hora que tu chega numa situação como essa, é a oportunidade de eles devolverem tudo que você passou pra eles aqui na Instituição [grifo nosso]. (Entrevistado 6).

Os discursos sinalizam, ainda, vivências de prazer por manter, depois de tantos anos, um projeto de extensão que é renomado e premiado internacionalmente, como também a oportunidade de contribuir com a comunidade com o projeto em questão. 
Eu dou cursos de extensão, eu já conheço o mundo inteiro, na China, em Londres, sou muito solicitada. Estou indo pro Rio agora pra dar um treinamento no curso de extensão. E essa é a minha história, o tempo todinho sou convocada pra ir, sou muito homenageada [grifo nosso]. A gente vê sempre os agradecimentos, eu recebo muitas cartas agradecendo (Entrevistada 5 ).

Outro relato de um entrevistado trata de um convite de retorno ao trabalho, interpretando a convocação como reconhecimento do seu compromisso com a Instituição.

Olha você está convidado para ser voluntário, aí mandou baixar e vir pegar o documento, aonde eu queira ficar, viu? Foi uma deferência, eu achei, foi uma deferência, não sei se foi especial, mas talvez pelo compromisso que a gente tem com a universidade, teve e tem com a universidade. (Entrevistado 1).

Mendes e Duarte (2013, p. 19) afirmam que o trabalhador, ao vivenciar o reconhecimento, “[...] se sente aceito, admirado, podendo de fato usufruir do trabalho como espaço para (se) construir, para se expressar e não só produzir para sobreviver". O trabalho, portanto, quando desarticulado de um vínculo salarial, pode se tornar fonte de prazer ao ser vivenciado como forma de expressão e realização pessoal.

Identifica-se a vivência de reconhecimento no exercício da docência como propiciadora de sentido de vida para os participantes dessa pesquisa. E, no contraponto, sinaliza-se o sofrimento atrelado à experiência de ser "dispensado" do trabalho na sociedade capitalista. O aposentado normalmente se sente excluído ao ocupar o "não lugar" em uma sociedade que exalta o sujeito produtivo e discrimina quem se afastou do labor.

Neste sentido, vale analisar as razões que levam os docentes a não romperem com a vida acadêmica e, dentre elas, pode-se destacar a temida inatividade. Será que permanecem na docência pelo receio de perder o reconhecimento? Há temor frente à possibilidade de ocupar o "não lugar" de uma vida de aposentado atravessada por estereótipos de inutilidade, de obsolescência e ociosidade?

\section{O Processo de Aposentadoria e a Temida Inatividade}

Roesler (2012) aborda a aposentadoria enquanto um processo, que se inicia antes da desvinculação com a organização do trabalho, e perdura até depois da sua efetivação. Esta autora visualiza o processo de aposentadoria em duas óticas: objetiva e subjetiva. Na primeira, trata-se do desligamento burocrático oficializado institucionalmente; na segunda, tem-se o afastamento das relações sociais, bem como da identidade profissional construídas no tempo de serviço.

Com o envelhecimento, a inatividade pode se configurar em um estereótipo de alguém 
que, por não contribuir mais economicamente, ocupa um lugar de afastamento, de ausência, de uma função social. Roesler (2012, p. 111), ao relacionar aposentadoria e velhice, ressalta que, nos moldes do capitalismo, há "uma representação coletiva de obsolescência, ao conceber o sujeito que envelhece como incapaz de continuar produzindo bens e serviços; dito de outra forma, a partir desta perspectiva o aposentado perde sua 'utilidade' e torna-se um peso social'.

\begin{abstract}
Porque a velhice, que vem junto com a aposentadoria, ela atrai essas coisas, porque você pressupõe que você está completamente sem sentido na vida. Você passa a sero quê quando você se aposentar? Você não vai ser psicóloga aposentada, não, você é uma aposentada. Eu não sou professor aposentado, eu sou um aposentado. Aífica como se fosse um carimbo na tua testa. Fulano de tal é aposentado, o quê que é o aposentado? [grifo nosso]. Ninguém sabe o que faz com o aposentado, mas aí o aposentado, às vezes, não concorda muito com essa nomeação que a sociedade impõe, que a aposentadoria só acaba na ociosidade (Entrevistado 6).
\end{abstract}

Os efeitos desse rompimento das relações de trabalho são inquestionáveis, pois aposentar-se não é apenas o término da carreira, é também uma interrupção de atividades praticadas durante muitos anos, o que implica também no rompimento dos vínculos sociais.

\begin{abstract}
Eu acho que eu tive, confesso, um pouco de medo disso, em função das características do meu trabalho e da minha história. Então agora é como se eu tivesse começando a me preparar pra isso. Tenho que encontrar outros sentidos, pra que quando tudo isso desaparecer, eu não vá me sentir tão empobrecida, sem sentido, desnecessária [grifo nosso]. É uma série de coisas que estão implicadas nessa decisão [de se aposentar definitivamente] (Entrevistada 2).
\end{abstract}

O único docente entrevistado que se afastou do trabalho ao formalizar a aposentadoria, relatou que adoeceu nesse período:

Quando eu aposentei, de imediato eu adoeci, passei quase dois anos e meio sem atividade, operei de próstata, operei de coluna, operei de, teve problema articular que eu nem podia caminhar, aí foi o único impacto, foi na saúde... a cabeça psicologicamente, filosoficamente, estava aqui no sentido de continuarfazendo esse trabalho(Entrevistado 1).

Em consonância com a literatura que aponta o caráter central do trabalho na sociedade (Antunes, 2005; Navarro \& Padilha, 2007; Alves, 2007; Castel, 1998), e o sentido que é atribuído tanto individual quanto socialmente, foi percebida a relevância do lugar que o trabalho ocupa na vida dos entrevistados. A necessidade de se manterem ocupados foi apontada como fator incisivo na escolha pelo retorno. A maioria dos entrevistados nem teve um real afastamento do trabalho após a aposentadoria, permanecendo em atividade.

Alguns participantes caracterizaram esse momento de continuidade no trabalho como uma oportunidade de desligamento do cotidiano laboral de forma menos abrupta: 
Eu tenho dito que eu vou fazer uma transição, uma outra transição, para me afastar completamente. Aí um afastamento que eu vou me preparar é como se eu tivesse, do ponto de vista mais pessoal, me preparando de vez para me afastar de algo que é sua vida [grifo nosso], de 30, 40 anos, não é uma coisa. Estou tentando encontrar um prazo, que no momento aparece pra mim como até a próxima jornada de políticas públicas daqui a dois anos. Acho que é um tempo de preparo pessoal, emocional pra eu fechar todas essas coisas que fazem parte de você [grifo nosso]. (Entrevistada 2).

Eu só estou na pós-graduação, em 3 programas, eu vejo isso como um desmame [grifo nosso], onde eu vou me afastando aos poucos do trabalho (Entrevistada 4).

Ao retornarem após a formalização da aposentadoria, argumentaram que realizam atividades mais prazerosas, e se afastam daquelas consideradas mais desgastantes, pois têm a opção de escolher o que querem fazer e onde querem continuar contribuindo. Nos relatos de 4 (quatro) entrevistados, percebe-se essa opção por retornar em atividades que lhes dão mais prazer:

Após aposentado estou dando outras disciplinas ligadas a história e ciências sociais, a antropologia, gestão e planejamento. É gratificante, porque eu estou dando aula daquilo que eu tenho experiência também, da minha luta do movimento negro (Entrevistado 1).

A diferença de antes pra agora, é que agora eu não estou mais na graduação, a graduação consome muito o professor. A diferença também é que não participo de assembleias de departamento, as assembleias são muito dificeis, são momentos de muitos embates e conflitos, é muito desgastante (Entrevistada 4).

Ele [o trabalho] tem sido mais voltado, porque enquanto eu estava na sala de aula, eu tinha menos tempo pra esse trabalho. Eu não tinha muito tempo pra isso, agora não, eu estou dedicada só a isso, passo o tempo todinho dando [atendimento] (Entrevistada 5).

Então o meu papel aqui é uma presença assim, eu sou tipo um consultor eu moro aqui do lado do campus, então não tem nenhuma dificuldade de eu vir aqui, não precisa correr muito (Entrevistado 6).

Os entrevistados relatam que o retorno ao trabalho é mais leve, sem cobranças, e, consequentemente, menos intensificado do que enquanto estavam como docentes ativos:

Os professores colaboradores, que trabalham, mas com uma certa autonomia pra definir as suas atividades no programa. E é nessa forma que eu me encontro no momento vinculada (Entrevistada 2).

Agora eu me sinto mais livre pra fazer o que eu quiser, na hora que eu quiser. Hoje eu me sinto mais livre pra dormir, me alimentar, eu gosto muito de dormir depois do almoço. Eu posso viajar por interior no final de semana, ir na sexta, voltar só no domingo (Entrevistada 4).

Apesar deste retorno ser caracterizado na fala dos entrevistados como volta a uma atividade laboral diferenciada, devido ao vínculo de trabalhador voluntário, os docentes revelam um discurso contraditório. Sinalizam certa autonomia nas atividades desempenhadas, 
mas deixam transparecer uma rotina intensificada, permeada, de modo preponderante, pelo tempo dedicado ao trabalho:

\begin{abstract}
De algum modo, os vínculos que você assume, você se livra das obrigações contratuais, mas se mantém ainda sob a determinação dos compromissos acadêmicos [grifo nosso]. Daqui a pouco vai chegar uma orientanda minha que ela tem um prazo pra defender sua dissertação de mestrado. Então de algum modo, a rotina, ela continua forte, num dado momento eu digo "essa rotina já tá pesada" [grifo nosso] (Entrevistada 2).
\end{abstract}

Todos os dias eu tenho alguma coisa pra fazer, às vezes me encontrar comorientando, preparar aula da pós, quando eu não estou aqui, eu estou trabalhando em casa, porque professor trabalha muito em casa. O máximo que um professor pode ter de orientandos são 8, e vocês não vão acreditar, eu tenho 8 (Entrevistada 4).

Tem dia que eu saio daqui nove horas da noite, tem dia que eu atendo 20 pessoas de manhã, 20 à tarde, passo o dia praticamente aqui. Entro oito horas, saio sempre doze, aí tem dia que saio duas horas. Aí já três e meia, três horas já estou aqui, saio cinco, seis, sete, tem dia que saio nove horas da noite (Entrevistada 5).

Identifica-se uma dinâmica complexa no cotidiano desses docentes, constituída por sentimentos conflitantes, como medo de desprendimento e paixão. O discurso do "amor" pelo trabalho apresenta atenuantes para justificar a intensa rotina, da maioria, e a permanência na docência (Ribeiro \& Leda, 2016). A não ruptura com a Instituição alivia a angústia de enfrentar a temida inatividade, mas a decisão pela continuidade no ambiente acadêmico propicia vivências concomitantes de prazer e sofrimento. O grande desafio é avaliar ganhos e perdas de tão importante decisão.

\title{
Prazer e Sofrimento no Trabalho: "Se você se aposentar e não continuar tendo prazer na
} tua vida, você vai se aposentar pra quê?"

A Psicodinâmica do Trabalho pressupõe que o trabalho é mediador dos processos de saúde, mas também será sempre gerador de sofrimento ao sujeito. Mendes (2007) ressalta que a saúde mental no trabalho não está relacionada à ausência de sofrimento, mas às possibilidades de busca de prazer e/ou transformação dos fatores que causam sofrimento e adoecimento, e é nesta dinâmica prazer-sofrimento que se constitui o sentido do trabalho.

Quando questionados sobre o que lhes dá prazer no seu trabalho, os sujeitos entrevistados relatam:

O que traz prazer hoje no meu trabalho é o contato com os colegas e com os alunos, é continuar sendo produtiva, contribuindo (Entrevistada 4). 
Dar aula, discutir com aluno, conversar, trocar ideia, colocar a experiência que a gente tem, que é positiva, uma experiência que foi positiva, é essa a motivação (Entrevistado 1).

Sabe-se que a retribuição simbólica, mais do que a salarial, repercute nas vivências de prazer que o sujeito pode ter no trabalho (Dejours, 2011a). Percebe-se que a relação com os alunos, com os colegas de trabalho, o reconhecimento por parte de ambos, além de poder continuar contribuindo para a Instituição, foram alguns aspectos positivos elencados pelos entrevistados. Estes são alguns fatores que podem ser considerados como sendo elementos de grande motivação para o retorno desses professores ao trabalho, ainda que na ausência do vínculo formal e, portanto, sem receber mais nenhuma vantagem financeira.

Como fonte de sofrimento, os docentes relataram a questão da vaidade e do produtivismo acadêmico, como fatores que suscitam desavenças e competitividade entre os pares, o que não é favorável ao clima institucional, gerando mal-estar no trabalho. Contexto adverso identificado por Dejours (2011c), quando afirma que a falta de cooperação e o enfraquecimento do coletivo são geradores de sofrimento.

Os docentes entrevistados apontam como fonte de desprazer no ambiente da docência:

Assistir de fora uma briga entre os professores do departamento, por conta de vaidade. Isso é uma coisa que me deixa muito triste. A gente criou um departamento pra que as pessoas vivessem harmoniosamente, construindo um objetivo, mas aí isso é lá no século passado, a coisa muda (Entrevistado 6).

Uma coisa hoje que me parece altamente letal no trabalho acadêmico, pra atividade de pesquisa é esse produtivismo acadêmico esse produtivisimo acelera disputas, incentiva vaidades, eu penso que são coisas dificeis para a atividade de pesquisa (Entrevistada 2).

Tais relatos mostram que as relações de trabalho sofreram mudanças da época em que os docentes entrevistados iniciaram a sua carreira docente. É comum perceber em seus discursos que os dias atuais são bastante distintos, tanto em relação ao perfil dos professores quanto ao dos alunos.

Por terem feito parte da criação ou consolidação das graduações, é possível notar que há um forte sentimento de contribuição, uma vez que estes docentes entendem que selaram um compromisso com a universidade.

Nesse sentido, justifica-se a dificuldade de desligamento com o trabalho docente. Ao serem instigados a falar sobre o que pretendem fazer ao se aposentarem efetivamente do trabalho na Instituição, os entrevistados apontaram para algo que ainda se encontra em construção, como projetos para o futuro, planos não passíveis de serem colocados em prática em imediato: 
Eu pretendo escrever, de forma livre, porque na academia tudo é muito restrito, você tem que produzir para revista, não serve menos de B, pra você conseguir uma publicação em uma qualis A, é muito difícil. Então, eu pretendo escrever de forma livre (Entrevistada 4).

A Entrevistada 5 não se vê longe do trabalho e brinca: "Mas enquanto eu puder, tiver lúcida e puder ajudar, eu estou aqui, não tenha dúvida, e se os reitores me aturarem (risos)" (Entrevistada 5).

Nesse sentido, percebe-se a dificuldade de desligamento com o trabalho docente, visto que a entrevistada vê em seu trabalho a possibilidade de contribuir, pois há uma retribuição do que ela faz que é de ordem simbólica.

A quebra do vínculo empregatício e a efetivação da aposentadoria é um momento singular na vida do trabalhador, pois a forma como se constitui esta decisão vai afetar uma possível escolha do sujeito, podendo optar por permanecer no trabalho ou por caminhos distintos.

\section{CONSIDERAÇÕES FINAIS}

$\mathrm{Na}$ análise das razões que levaram os docentes inativos a permanecerem na Instituição, foram identificados depoimentos distintos que apontaram para o receio de experimentar sentimentos de inutilidade e superfluidade, diante do desafio de dar sentido a uma vida sem trabalho. O mais surpreendente é que a maioria dos entrevistados não tem nenhuma vantagem financeira com esse retorno, o que seria uma atitude incompreensível para muitos. Sobretudo, quando a categoria trabalho tende a ser reduzida na nossa sociedade a meio de sobrevivência econômica.

Constatamos que o sentido do trabalho e o vínculo que os docentes constituíram com a Instituição, são os maiores obstáculos para o desligamento da vida acadêmica. Parte dos entrevistados não chegou a se afastar efetivamente do trabalho (4 docentes); 2 (dois) que não possuem atividades definidas, e que continuam se dirigindo à Instituição com certa frequência, desenvolvendo atividades de caráter mais livre e autônoma; e 1 (um) que chegou a se afastar, mas foi convidado para retornar ao trabalho.

Muitos não percebem que estão em plena atividade de trabalhø, embora estejam como "voluntários", principalmente os docentes vinculados aos programas de pós-graduação e a docente que está vinculada à assistência da comunidade.

Somente 2 (dois) entrevistados planejaram a aposentadoria antes que esta fosse efetivada, sendo que a maioria deixou para pensar nesse assunto após a formalização da 
aposentadoria, utilizando-se do trabalho voluntário para facilitar um processo de desligamento gradual da Instituição. Os participantes falaram em necessidade de "desaceleração", de "desmame", além de uma associação feita entre vida acadêmica e "cachaça".

O desejo de continuarem sendo reconhecidos pelo que fazem é uma das principais motivações de continuidade no trabalho, demonstrando o medo de serem esquecidos ao se desvincularem por completo da Instituição para a qual já contribuíram tanto. Ao enfatizarem que o trabalho docente não é qualquer trabalho, e manifestarem dificuldades de desligamento desse papel, demonstram que a sua subjetividade já é tão marcada por esse lugar, o que os faz ter mais dificuldade de aceitação da aposentadoria.

O retorno simbólico desse investimento pessoal, que continua mesmo após os vínculos legais com o trabalho serem desfeitos por meio da aposentadoria é o que os faz continuarem engajados nessa tarefa de formar pessoas, de atender à comunidade, ou de simplesmente ir à universidade toda a semana, para acompanhar e contribuir de alguma forma para o curso que fizeram parte desde a implantação.

Além disso, percebe-se o sentimento de gratidão que esses sujeitos têm para com a universidade, pois a história desta se confunde com a história de vida deles e de seus engajamentos nas lutas para o desenvolvimento de uma educação de qualidade. Eles são os construtores dessa história que, muitas vezes, fica esquecida, e, talvez, de alguma forma, eles têm a esperança de que ela nunca se perca, principalmente enquanto eles ainda estiverem presentes para contá-la.

Destaca-se a importância de desenvolvimento de políticas de valorização e de reconhecimento de forma institucional dessas pessoas que construíram e lutaram desde a implantação dos seus cursos. Portanto é necessário que sejam enfatizadas a sua trajetória profissional e as suas contribuições no desenvolvimento da Instituição, para que isso fique registrado não somente na história de vida de cada um desses sujeitos, mas também na história da universidade que ajudaram a escrever.

\section{Referências}

Alves, G. (2007). Dimensões da reestruturação produtiva: ensaios da sociologia do trabalho.

São Paulo: Práxis. Retirado em 3/04/2019 de http://www.gio vannialves.org/DRP.pdf.

Antunes, R. (2005). O caracol e sua concha: ensaios sobre a nova morfologia do trabalho. São Paulo, Boitempo. 
Antunes, R. (2011). Adeus ao trabalho? Ensaio sobre as metamorfoses e a centralidade no mundo do trabalho. São Paulo: Cortez.

Borges, L. O., \& Yamamoto, O. H (2004). O mundo do trabalho. In J. C. Zanelli, J. BorgesAndrade, \& A. V. B. Bastos (Orgs.), Psicologia, organizações e trabalho no Brasil (pp. 24-62). Porto Alegre: Artmed.

Castel, R. (1998). As metamorfoses da questão social: uma crônica do salário. Petrópolis: Vozes.

Dejours, C. (2004). Subjetividade, trabalho e ação. Revista Produção, 14(3), 27-34. Recuperado de: https://dx.doi.org/10.1590/S0103-65132004000300004.

Dejours, C., \& Abdoucheli, E. (2007). Itinerário teórico em psicopatologia do trabalho. In C. Dejours,; E. Abdoucheli, \& C. Jayet, (Orgs.), Psicodinâmica do trabalho: contribuições da escola dejouriana à análise da relação prazer, sofrimento e trabalho (pp. 119-145). São Paulo: Atlas.

Dejours, C. (2011a). Da Psicopatologia à Psicodinâmica do Trabalho. In S. Lancman, L. I. Sznelwar \&, C. Dejours (Orgs.), Da psicopatologia à psicodinâmica do trabalho (pp. 57124). Rio de Janeiro: Fiocruz.

Dejours, C. (2011b). Entre sofrimento e reapropriação: o sentido do trabalho. In S. Lancman, \& L. I. Sznelwar (Orgs.), Da psicopatologia à psicodinâmica do trabalho (pp. 433-448). Brasilia: Paralelo 15/ Rio de Janeiro: Fiocruz.

Dejours, C. (2011c). O trabalho como enigma. In S. Lancman, \& L. I. Sznelwar (Orgs.), Da psicopatologia à psicodinâmica do trabalho (pp .151-166). Brasilia: Paralelo 15/ Rio de Janeiro: Fiocruz.

Fairclough, N. (2008). Discurso e mudança social. Brasîlia: UNB.

França, L. H. F. P., Menezes, G. S, Bendassolli, P. F., \& Macedo, L. S. S. (2013). Aposentarse ou continuar trabalhando?: o que influencia essa decisão?. Psicologia: Ciência $e$ Profissão, 33(3), 548-563. Recuperado de: https://dx.doi.org/10.1590/S141498932013000300004.

Fraser, M. T. D., \& Gondim, S. M. G. (2004). Da fala do outro ao texto negociado: discussões sobre a entrevista na pesquisa qualitativa. Revista Paidéia, 14 (28), 139-152. Recuperado de: https://dx.doi.org/10.1590/S0103-863X2004000200004.

Freire, F. M. L., Oliveira, M. L., Sousa, L. M., Salgado, L. F. C., \& Ribeiro, C. V. S. (2018). As repercussões do processo de aposentadoria na subjetividade de docentes de uma instituição federal de ensino superior. In J. V. Sousa, A. F. Botelho \& C. M. Griboski (Orgs.), Trabalho docente na expansão da educação superior (pp 98-111). Anapólis: UEG.

Gonçalves, M. da G. M. (2003). A contribuição da psicologia sócio-histórica para a elaboração de políticas públicas. In A. M. B. Bock (Org), Psicologia e compromisso social (pp. 277293). São Paulo: Cortez. 
Martins, S. R. (2013). Subjetividade (Intersubjetividade). In F. O. Vieira, A. M. Mendes \& A. R. C. Merlo (Orgs), Dicionário Crítico de Gestão e Psicodinâmica do Trabalho (pp. 433438). Curitiba: Juruá.

Martins, S. R. (2008). Tempo antes do adoecer: relações entre saúde e processos psicodinâmicos do reconhecimento do trabalho. In A. M. Mendes (Org), Trabalho e Saúde: o sujeito entre emancipação e servidão (pp. 69-88). Curitiba: Juruá.

Mendes, A. M., \& Duarte, F. S. (2013). Mobilização Subjetiva. In F. O. Vieira, A. M. Mendes, \& A.R.C. Merlo (Orgs.), Dicionário crítico de gestão e psicodinâmica do trabalho (pp. 259-262). Curitiba: Juruá.

Mendes, A. M. (2007). Da psicodinâmica à psicopatologia do trabalho. In A. M. Mendes (Org.), Psicodinâmica do Trabalho: teoria, método e pesquisas (pp. 29-59). São Paulo: Casa do Psicólogo.

Navarro, V., \& Padilha, V. (2007). Dilemas do trabalho no capitalismo contemporâneo. Psicologia e Sociedade, 19(spe), 14-20. Recuperado de: https://dx.doi.org/10.1590/S0102$\underline{71822007000400004 .}$

Ramos, M., Tittoni, J., \& Nardi, H. (2008). A experiência de afastamento do trabalho por adoecimento vivenciada como processo de ruptura ou continuidade nos modos de viver. Cadernos de Psicologia Social do Trabalho, 11(2), 209-221. Recuperado de: https $/ /$ doi.org/10.11606/issn.1981-0490.v11i2p209-221.

Ribeiro, C. V. S., \& Leda, D. B. (2016). O trabalho docente no enfrentamento do gerencialis mo nas universidades federais brasileiras: repercussões na subjetividade. Educação em Revista, 32 (4), 97-117. Recuperado de: https://dx.doi.org/10.1590/0102-4698161707.

Ribeiro, C. V. S., \& Leda, D. B. (2018). Sentidos atribuídos ao trabalho na sociedade contemporânea e as repercussões na subjetividade do trabalhador. Revista Espaço Acadêmico, 211(1), 39-49. Recuperado de: http://ojs.uem.br/ojs/index php/EspacoAcademico/article/viewFile/45047/751375138736.

Roesler, V. R. (2012). Posso me aposentar "de verdade", e agora? Contradições e ambivalências vividas no processo de aposentadoria de bancários (Tese de Doutorado). UFSC, Florianópolis, Santa Catarina, Brasil.

Santos, M. F. S. (1990). Identidade e aposentadoria. São Paulo: EPU.

Silva, E. P., \& Heloani, R. (2007). Aspectos teóricos e metodológicos da pesquisa em saúde mental e trabalho: reflexões a partir de uma análise comparativa do estresse em jornalistas e guardas municipais. Cadernos de Psicologia Social e do Trabalho, 10(01),105-120. Recuperado de: https://doi.org/10.11606/issn.1981-0490.v10i1p105-120.

Zanelli, J C., Silva, N., \& Soares, D. H. P. (2010). Orientações para a aposentadoria nas organizações de trabalho: construção de projetos para a pós-carreira. Porto Alegre: Artmed. 